\title{
Apontamentos sobre a criação crítica de Gilda de Mello e Souza em A idéia e o figurado
}

\section{Notes about the critic creation of Gilda de Mello e Souza in The idea and the figurative}

\author{
Carlos Henrique dos Santos Fernandes \\ Graduando, Curso de Bacharelado em Filosofia, Universidade Federal de São Carlos - UFSCar, \\ São Carlos, SP, Brasil.
}

\begin{abstract}
Resumo: O objetivo deste artigo é apresentar a atividade de Gilda de Mello e Souza (1919-2005) em seus últimos ensaios como um dos mais reinventivos exercícios críticos que temos sobre literatura, espetáculo, artes visuais, escultura, fotografia, cinema e dança. Para isso, analisamos o conjunto dos ensaios presente em A idéia e o figurado (2005). Por um lado, sugerimos três elementos estruturais da crítica da ensaísta, a saber, "o objeto concreto", "os traços desimportantes" e "a decifração de códigos"; por outro lado, buscamos relacionar essas estruturas, respectivamente, à formação da revista Clima, à proximidade ao método indiciário de Giovanni Morelli e à aplicação permanente e relativa da iconografia e da iconologia de Erwin Panofsky. Acreditamos que, em A idéia e o figurado, a crítica de Mello e Souza constrói-se, no mínimo, pela presença desses três elementos supracitados, além de aclimatar e atualizar as abordagens desses dois críticos de arte, reinventando a reflexão artística brasileira de seu tempo e porvir.
\end{abstract}

Palavras-chave: decifração de códigos; Gilda de Mello e Souza; objetos concretos; traços desimportantes.

\begin{abstract}
The objective of this article is to present the activity of Gilda de Mello e Souza (1919-2005) in her last essays as one of the most reinventive critics exercises that we have about literature, spectacle, visual arts, sculpture, photograph, cinema and dance. For this, we analyze the group of the essays present in The ideia and the figurative (2005). On the one hand, we suggest three structural elements of the essayist's critic, including "the concrete object", "the unimportant traits" and "the deciphering codes"; on the other hand, we seek to relate these structures, respectively, to the structuralization of the magazine Clima, to the proximity to the Giovanne Morelli's indiciary method and to the Erwin Panofsky's permanent and relative iconography and iconology application. We believe that, in The ideia and the figurative, the Mello e Souza's critic is built, at least, for the presence of these three elements aforementioned, beyond to acclimatize and to refresh the approach of these two art critics, reinventing the brazilian artistic reflection of her time and the time to come.
\end{abstract}

Keywords: deciphering codes; Gilda de Mello e Souza; concrete objects; unimportant traits. 
Ser sensível aos signos, considerar o mundo como coisa a ser decifrada é, sem dúvida, um dom. (Deleuze, Proust e os signos, p. 25)

Os apontamentos que seguem a princípio foram discussões da disciplina de estética, do curso de graduação em filosofia, dedicada a Gilda de Mello e Souza, ministrada no $2^{\circ}$ semestre de 2015 pelo Prof. Dr. Luís Fernandes dos Santos Nascimento, do Departamento de Filosofia e Metodologia das Ciências (DFMC), da Universidade Federal de São Carlos (UFSCar) - São Carlos - SP. Meu agradecimento aos colegas e professor.

\section{Os objetos concretos}

A idéia e o figurado é o último livro publicado, em vida, por Gilda de Mello e Souza. Organizada pela autora, com o auxílio de Augusto Massi ${ }^{1}$, a obra reúne modestamente quatorze ensaios, datados desde 1983, com Duas notas: João Câmara Filho e Gregório Gruber, até o ano de 2005, com o inédito Notas sobre Fred Astaire. Dividida em duas seções, encontramos, na primeira parte, cinco escritos dedicados à vida, à personalidade e, sobretudo, à produção intelectual de Mário de Andrade (primo irmão do pai de Gilda), ao passo que a segunda parte, constituída por nove ensaios, sugere uma série de temas: literatura, espetáculo, artes visuais, escultura, fotografia, cinema e dança.

Em todos os escritos de A idéia e o figurado percebemos que o desenvolvimento das críticas da autora toma como objeto de investigação algo concreto e não uma teoria (como costumamos ver, sobretudo, nos círculos acadêmicos com suas especializações). Folheando rapidamente o livro já podemos perceber essa peculiaridade que se repetirá em todos os ensaios: o uso direto, mesmo que fragmentado, de objetos visíveis.

Em outras palavras, diferente de muitos tratados ou artigos científicos tradicionais, que primam pela abstração, $A$ idéia e o figurado contém e analisa reproduções fotográficas de comemorações festivas ou de cerimônias, de salões e suas decorações, de cerâmicas ou de filmes, assim como a reprodução de pinturas, trechos de cartas, de romances, de contos ou de poesias, além de passagens de diários de viagem e fragmentos de entrevistas.

Repassando os olhos com mais vagar nesta coletânea, vemos sobressaltar, ainda mais, o gosto frequente da ensaísta pelo visível. Por isso, alguns exemplos nesse sentido podem nos ajudar a compreender o modo como consideramos, em Mello e Souza, a sua opção deliberada pelo estudo de casos concretos.

Em O professor de música, Mello e Souza nos apresenta, inicialmente, duas fotografias em que o poeta modernista Mário de Andrade aparece. Elas não são o tema principal do ensaio, mas, mesmo operando obliquamente no texto como introdução ao tema, as fotografias ilustram a situação dupla de Mário durante o período da Semana de Arte Moderna, de 1922. As descrições das duas fotografias feitas pela ensaísta - a primeira retratando os professores do Conservatório de São Paulo e a segunda retratando os companheiros modernistas da Semana de 22 - são brilhantes. A iconografia é reveladora a ponto de cativar seus leitores, tanto que, independente da continuação do ensaio e de seu desenvolvimento a respeito da atuação de Mário no magistério, com o comentário do quinto capítulo do compêndio (o qual, aliás, a autora prefacia), já nos damos por convencidos de seu ofício acanhado de professor de música em contraste com a sua agitação revolucionária e sua atuação como um dos líderes do movimento modernista. Desse modo, as descrições destas fotografias,

\footnotetext{
${ }^{1}$ Cf. nota de agradecimento da autora, em A ideia e o figurado, p. 179. Além disso, Augusto Massi também escreve às abas do referido livro.
} 
neste período, trazem consigo mesmas o campo da realidade, do acontecimento, do visível de que falamos em Mello e Souza.

Outro exemplo. Após a exposição das fases da poesia marioandradina, o poema "Brasão", de Mário de Andrade, citado no final do ensaio A poesia de Mário de Andrade, assim como o poema "Carta de Brasão", de Manuel Bandeira, exemplificam o contraste da poética cifrada do primeiro escritor em relação à poética mais enxuta do segundo. Destes poemas, Mello e Souza conclui a apresentação de sua antologia dos poemas de Mário de Andrade, revelando um dos mascaramentos do "eu atormentado" (MELLO E SOUZA, 2005, p. 31) do poeta paulistano, como o próprio confessa em cartas parcialmente citadas por Mello e Souza -, que se disfarça atrás de referências sobre o Brasil. Este novo exemplo ressalta, agora com a descrição da ensaísta sobre estes poemas, citados integralmente no referido ensaio, e destes poetas especificamente, elementos materiais que nos permitem observar, mais uma vez, a preferência de Mello e Souza por uma interpretação de princípio sensível, concreto.

Ademais, esta característica que observamos, diríamos, de ir "às coisas mesmas" não é exclusividade das reflexões de Mello e Souza sobre Mário de Andrade, reunidas na primeira seção de $A$ idéia e o figurado ${ }^{2}$. Na seção seguinte esse gosto pelo "objeto concreto" é tão nítido quanto exponencialmente expandido pela ensaísta, já que seu olhar crítico inclina-se, também, às produções artísticas variadas, sobretudo às criações de artistas femininas, como ocorre com as análises da escrita de Zulmira Ribeiro Tavares, em As migalhas e as estrelas, das pinturas de Rita Loureiro, em Rita Loureiro reinventa a pintura, das cerâmicas de Sara Carone, em Feminina, táctil, musical e das fotografias de Madalena Schwartz, em Uma artista exemplar. Vejamos apenas uma destas análises.

Em Rita Loureiro reinventa a pintura, a ensaísta analisa duas séries da pintora: a primeira, de 1981, é a sequência de quadros "Macunaíma" e, a segunda, de 1984, é a "Boi tema". Quando analisa o conjunto dessa segunda série, Mello e Souza escolhe três quadros como exemplares da criação da pintora. Os quadros "Boi Marrequeiro" e "Boi Piranha", com suas filas de marrecas e de bois, respectivamente, na interpretação da ensaísta, explicam a predileção de Rita Loureiro pela "representação sucessiva, a enumeração, a repetição" (MELLO E SOUZA, 2005, p. 129). Já o terceiro quadro, o "Mega Boi", além de exemplificar a mesma preferência de Rita pela fila, com sua fila de cavaleiros, também justifica a aproximação do folclore brasileiro, no caso o do Bumba-meu-Boi, retratado e renovado pela pintora, com a revitalização da pintura de raízes medievais pelo período renascentista do Quattrocento. Com esses exemplos específicos, desta exposição, destes quadros e desta pintora, Mello e Souza dedica-se aos casos concretos, sensíveis que dão uma ideia geral e precisa do estilo renovador da pintora. Mas, mais do que a pintura ser renovada pelas mãos da artista manauara, vemos esta ser renovada pelo quadro inovador que Mello e Souza dela faz, levando-a da "arte ingênua", na qual foi classificada erroneamente, para o nível da "grande arte", ou seja, Gilda de Mello e Souza com sensível sabedoria reinventa Rita Loureiro e sutilmente a reapresenta dentro do panorama brasileiro das artes plásticas.

Se com os exemplos supracitados tentamos revelar o afeto de Mello e Souza pelo objeto concreto, não podemos deixar de observar que este interesse foi também compartilhado pela sua geração, mais especificamente pelo grupo da revista Clima, a qual durou de 1941 a 1944. O tom "apaixonado" pelo fenômeno que encontramos em A idéia e o figurado já se fazia notar desde a criação desta revista, cujos integrantes mais proeminentes eram: Antonio Candido (na seção de literatura), Décio de Almeida Prado (na seção de teatro), Paulo Emílio Salles Gomes (na de cinema), Lourival Gomes

\footnotetext{
2 Embora Mário de Andrade apareça na segunda parte de A ideia e o figurado, isso se dá de modo secundário, como nos ensaios Rita Loureiro reinventa a pintura (pp. 125-137) e Lasar Segall e o modernismo paulista (pp. 95-112).
} 
Machado (na de artes plásticas), entre outros colaboradores, como a própria Gilda de Mello e Souza (na seção de contos).

Deslocando-nos brevemente da coletânea analisada, tentemos aprofundar um pouco esta relação de Mello e Souza com a revista Clima, mais precisamente com um de seus colaboradores ilustres, para compreender o modo de seu pensar e fazer crítico. Num ensaio de 1978-1979, intitulado Paulo Emílio: a crítica como perícia, em Exercícios de Leitura, Mello e Souza escreve:

[...] é esclarecedor passar os olhos com a atenção pelos dezesseis números de Clima, publicação que cobre o período de maio de 1941 a novembro de 1944 e que do número 1 ao 8 sai todos os meses, sabe-se lá por obra de que milagre. A revista é eclética e, no início, sem muita unidade, mas seus colaboradores mais chegados apresentam uma característica comum: fazem uma crítica apoiada na análise das obras e não na discussão das posições teóricas. (MELLO E SOUZA, 2009a, p. 261, itálicos nossos)

Embora dedique-se a aproximar o método de Paulo Emílio da peritagem, o ensaio acaba circunscrevendo a própria formação intelectual da autora e de sua geração de "recém-formados em filosofia e ciências sociais" que compuseram o grupo Clima, "denunciando" um traço comum de seus integrantes, a saber, o gosto pelo concreto, que vínhamos atribuindo apenas a Mello e Souza.

O caso de Paulo Emílio é curioso e revelador. Isto porque Paulo Emílio influenciou a revista Clima antes mesmo de ela existir, como declara Mello e Souza no mesmo ensaio: "Foi com Paulo Emílio que a minha geração aprendeu o que era cinema [...]". Essa influência iniciou-se em um "grupo restrito de amigos" e depois se ampliou com o "Clube de Cinema da Faculdade de Filosofia e da seção cinematográfica de Clima" (MELLO E SOUZA, 2009a, p. 260). Para nossa ensaísta, do pequeno grupo até à revista, Paulo Emílio não mudou seu método crítico nem seu estilo, que "prefere se debruçar sobre o filme na moviola. O que o preocupa é o real, o concreto, a obra, o que ela diz sobre o mundo, como o autor fala por seu intermédio" (MELLO E SOUZA, 2009a, p. 262).

Assim sendo, a predileção de Mello e Souza pelo objeto concreto, e não pelas teorias em voga ou pelas discussões teóricas, nasce tanto de seu temperamento quanto de sua formação intelectual e da de sua geração, como vimos pela figura de Paulo Emílio no grupo da revista Clima. É a " "paixão pelo concreto', que na expressão feliz de Antonio Candido define desde o início o pequeno grupo da revista" (MELLO E SOUZA, 2009a, pp. 260-61) - e pelo qual Mello e Souza continuará apaixonada até seu ensaio inédito sobre Fred Astaire publicado no ano de 2005, em A idéia e o figurado.

\section{Os traços desimportantes}

A escolha de Gilda de Mello e Souza a favor do objeto concreto, e não do abstrato, pode ser vista como uma crítica à formação especializada, teórica, sistemática, para a qual ela e seus amigos universitários não foram "talhados". Nesse sentido citamos um trecho em que a autora, ainda em Paulo Emílio: a crítica como perícia, avalia qual foi o resultado daqueles que escolheram enveredar pelo caminho "das coisas, do real, dos acontecimentos e das obras":

Líamos os criadores, não os teóricos da literatura, e nos interessávamos por todas as manifestações da arte, frequentando o cinema, o teatro, os concertos, as exposições de quadros, o circo, o ballet. E se a nossa geração não produziu nenhum filósofo, nenhuma cabeça teórica, foi sem dúvida uma geração de críticos que inaugurou entre nós a crítica moderna de teatro e de cinema, retomando em bom nível os estudos anteriores de música, literatura e artes plásticas (MELLO E SOUZA, 2009a, p. 261). 
Não só a escolha pelo concreto, mas também o exercício prático, centrado nos "traços desimportantes" das obras analisadas, reforça essa crítica ao campo das discussões especializadas. A busca pela prática da arte mais do que pela teoria, caracteriza, segundo Mello e Souza nesse texto em homenagem a Paulo Emílio, a carreira do perito. Como escreve, seguindo a definição de Lionello Venturi, o perito:

Possui conhecimento exaustivo de um período dado, em cujo contexto focaliza a obra; sabe confrontar e distinguir, de modo crítico, a escola, a personalidade, o estilo do artista; tem por objetivo final estabelecer ou retificar através da análise comparada, do cotejo estilístico, a atribuição (MELLO E SOUZA, 2009a, p. 263).

Ora, neste ensaio, Mello e Souza aproxima a figura do perito do método crítico de Paulo Emílio; contudo, não poderíamos aproximá-la também da tarefa interpretativa de nossa ensaísta? É o que faz Arantes ${ }^{3}$ em seu ensaio Notas sobre o método crítico de Gilda de Mello e Souza. Mas, antes de analisarmos o artigo de Otília, voltemos à obra A idéia e o figurado e vejamos ao menos dois exemplos de como ocorrem esses traços não muito notados e tão importantes para o exercício "minucioso" e "paciente" de um perito.

Em Duas notas: João Câmara Filho e Gregório Gruber, é interessante ler o curioso momento de criação do pintor Gregório Gruber, como se o surpreendêssemos em seu ateliê - mesmo sabendo que Mello e Souza toma como fonte de investigação um "documentário amador", no qual Gruber é filmado pintando. Mas, acontece que a ensaísta se detém menos ao que é criado, ao produto final, à tela, do que ao como é criado:

[...] a coreografia dos gestos e o ritmo amplo e amoroso do traçado, o empenho com que as mãos espalmadas espalhavam rapidamente o pigmento colorido na superfície do papel e como, em seguida, cada dedo, cada mão, dava a pequenos detalhes o certeiro toque final (MELLO E SOUZA, 2005, pp. 120-21).

Nesta abordagem da técnica do pintor, a autora enfatiza a característica do trabalho não policiado de Gregório Gruber em relação à tela, que, no entanto, não deixa de insinuar suas intenções enquanto artista, como "o sentimento de bloqueio e o imperativo da evasão" (MELLO E SOUZA, 2005, p. 121) em seus quadros, ressignificando, assim, os gestos antes insignificantes.

Já numa leitura apressada pelas linhas de Notas sobre Fred Astaire, concluiríamos que se trata de mais um ensaio exemplar de Mello e Souza, curto, elegante e enigmático. Mas bastaria fechar os olhos e retomar a leitura, para, aí então, ouvir as notas suaves com a autora, em seu último ensaio em vida, metamorfoseada em regente, ordena a orquestra dos gestos do bailarino Fred Astaire. Isso porque o texto mais que escrito, diríamos, foi composto, como se tratasse de uma partitura, como parece sugerir a própria numeração do ensaio, com suas 7 notas.

Ouvidas neste sentido, as comparações, aparentemente descompassadas da ensaísta, tornam-se comparações afinadas. Pois, em meio à poluição sonora das duas grandes guerras do século XX (que o tom existencial e angustiante de Beckett traduziu em arte com Esperando Godot e que Chaplin em suas atuações verteu em crítica social), os gestos de Astaire vibram, sob o comando de nossa regente, com alegria do começo ao fim do ensaio, sendo a última nota o gran finale de sua reflexão crítica.

Em outras palavras, se nesta última obra prima, Mello e Souza é compositora e, nesta criação harmoniosa, o bailarino dança no compasso ritmado pela "regente", formado pela melodia pura e harmoniosa de suas palavras, tudo isso ressoa em

${ }^{3}$ Otília Beatriz Fiori Arantes foi aluna dos cursos de estética ministrados por Gilda de Mello e Souza na USP, nos anos 60, e também por ela orientada, vindo a substituí-la "formalmente" em 1973, com a aposentadoria de Gilda (cf. Entrevista com Otília Beatriz Fiori Arantes. In: Rapsódias, pp. 221-264, notadamente, pp. 222-26). 
razão dos gestos. Os gestos ritmados do bailarino são uníssonos ao mundo em que vive e é por isso que o vemos, como se fosse uma tradução deste mundo, "subir e descer pelas paredes", como acontece no filme Royal Wedding (1951) ou "inverter a utilidade de cada objeto" (MELLO E SOUZA, 2005, p. 171), sem qualquer sentimento de oposição ou conflito. O que leva a ensaísta a considerar Astaire como o próprio gesto: "gesto puro, graça pura, arte pura" (MELLO E SOUZA, 2005, p. 177).

De fato, parece que Mello e Souza se interessa - assim como Paulo Emílio - pelos traços ou gestos desimportantes, evidentes nos exemplos supracitados, como um bom perito em seu exercício crítico, "centrado na observação das características mais insignificantes [...]" (MELLO E SOUZA, 2009a, p. 263).

Caminhando nesta direção de proximidade da peritagem, além de também apontar a sensibilidade da ensaísta em reconhecer em Paulo Emílio esses elementos, Arantes associa-a a um dos mais conhecidos peritos, cujo método era "congenitamente" próprio a Gilda de Mello e Souza, qual seja, "o método indiciário praticado pelos connaisseurs, notadamente pelo mais conhecido deles, o médico italiano do século XIX, Giovanni Morelli" (ARANTES, 2006, p. 38).

Arantes comenta que a "escolha meditada" da ensaísta, em valorizar em suas interpretações "os pequenos indícios", não a tornava uma perita "no sentido extremo do termo", pois, para ela, o interesse de Mello e Souza "não era exatamente o da atribuição de autoria da obra [...]" - tal como Morelli, questionando a autoria de várias obras - "mas de algo como a descoberta de 'códigos'" (ARANTES, 2006, p. 38). E este interesse pelos códigos aproxima-se, segundo ela, paralelamente de um segundo método prestigiado pela ensaísta: "a arqueologia visual dos mestres da escola de Warburg" (ARANTES, 2006, p.38), que discutiremos mais adiante.

Em toda a discussão levantada sobre esses dois métodos, Arantes toma em seu artigo, como referência, o livro Mitos, emblemas, sinais, de Carlo Ginzburg, destacando, por um lado, Morelli e o método indiciário e, por outro, Gombrich e o método arqueológico visual (mais precisamente da concepção da interpretação da obra de arte como sendo, sempre, mediada por esquemas ou "estruturas relacionais").

Introduzindo a questão, vale então dizermos, com Arantes, que, assim como acontece uma "aclimatação" por Mello e Souza do método indiciário de Morelli, já que se interessa pelos códigos e não pela atribuição, também poderíamos ver uma adaptação muito particular da ensaísta em relação ao método arqueológico visual da Escola de Warburg:

Pois é nesse vai vem entre a pintura, a sua história e a realidade que se move a nossa autora [Gilda de Mello e Souza] - utilizando permanentemente e ao mesmo tempo relativizando as lições dos mestres da Escola de Warburg (ARANTES, 2006, p. 42).

\section{A decifração dos códigos}

Ora, Prado Jr., em Entre Narciso e o colecionador ou o ponto cego do criador, cita a passagem que reproduzimos acima do artigo de Arantes, problematizando-o: "O que interessa é aprofundar o sentido dessa ligação de certo modo ambígua [de Gilda] com a referida Escola[de Warburg]: que significa aqui relativizar?" (PRADO JR., 2006, p. 29, itálico do autor).

Optando por comparar os textos "epistemológicos" de Erwin Panofsky com os ensaios de Gilda de Mello e Souza, próximos do esquema relacional de Gombrich, como faz Arantes em seu ensaio, Bento Prado Jr. busca aprofundar o estatuto paradoxal, ambíguo, de uso permanente e ao mesmo tempo relativo desses métodos pela ensaísta. Para compreender melhor esse problema seria interessante adentrarmos o campo da própria Mello e Souza, tentando antes visualizar em seus ensaios como os códigos aparecem e como por ela são decodificados. Vejamos dois exemplos. 
No ensaio de abertura Sobre O banquete $e^{4}$, de A idéia e o figurado, Mello e Souza nos indica que, enquanto "último momento da longa meditação", de Mário de Andrade, "sobre a Arte" (MELLO E SOUZA, 2005, p. 9), o poeta analisou o "drama intenso" do artista contemporâneo que tenta conciliar os "direitos desinteressados da arte pura" e "as intenções interessadas do homem social". Por isso, para a ensaísta, O banquete aparece como um grande código a ser decifrado em "vários níveis". O primeiro nível, e o mais superficial, é ler essa meditação como uma Crônica: "uma crônica dos costumes artísticos da época". (MELLO E SOUZA, 2005, p. 10).

Depois, em dois níveis mais profundos, apoiando-se na distinção metodológica de Luigi Pareyson, filósofo italiano do século XX, Mello e Souza apresenta o nível da Poética e o nível da Estética. Em resumo, a Poética estaria voltada para a atitude engajada de Mário de Andrade pela arte nacional, de combate, e a Estética estaria ligada à "análise dos elementos permanentes da arte: por exemplo, a distinção entre estética e estesia; o estudo da sensação estética; a distinção entre inovação e academismo; a curiosa classificação dos gênios [...]" (MELLO E SOUZA, 2005, p. 11), mas sobretudo, conforme a autora, o conceito de inacabado, que circularia entre a Poética e a Estética.

Assim como $O$ banquete, de Mário de Andrade, permite no mínimo três níveis de leitura - Crônica, Poética e Estética -, para Mello e Souza, um episódio fílmico também pode ser lido em três níveis. É o que vemos acontecer com as significações superpostas na pose de Veruschka, personagem do filme Blow-up (1966), analisado pela ensaísta em Variações sobre Michelangelo Antonioni.

Na sessão de pose da modelo, Mello e Souza desdobra em três níveis a sua interpretação. No primeiro nível, a cena exprime uma caricatura (charge) sobre "a obtenção da naturalidade numa fotografia de moda". No segundo nível, a cena expressa uma "crítica à elegância produzida da alta costura" que termina sendo consumida como qualquer outro artefato ou "mercadoria vulgar". No último nível, "talvez mais profundo", Thomas "montado" em Veruschka faz alusão "a uma posse amorosa", que, mesmo sendo "mecânica" e "descarnada", como aponta a ensaísta, "torna-se ofensiva como profanação à mulher" (cf. MELLO E SOUZA, 2005, p. 160).

Observados esses dois códigos e a maneira como Mello e Souza os decifra, em A idéia e o figurado, agora sim tentemos compreender, en passant, como Prado Jr. considera a relativização de Mello e Souza do método de interpretação de Panofsky, arriscando-nos ao mesmo tempo a encontrar possíveis aproximações relativas deste método com os exemplos supraelencados.

Detendo-se em um curto ensaio do crítico de arte, "Sobre o problema da descrição e da interpretação do conteúdo das obras de artes plásticas" ${ }^{\prime \prime}$, Prado Jr. nos apresenta o "esquema ternário" iconográfico (descritivo) e iconológico (interpretativo) proposto por Panofsky. Trata-se de uma "estrutura relacional", como já sugeria Arantes a respeito de Gombrich, com três níveis, os quais o crítico os nomeia em um quadro sinóptico de: "descrição pré-iconográfica, análise iconográfica e interpretação iconológica" (PANOFSKY, 2007, p. 64), sendo que cada um desses níveis também é desdobrado em outras três instâncias, que, em seus termos, são o "objeto da interpretação", a "fonte subjetiva da interpretação" e o "corretivo objetivo da interpretação" (cf. PRADO JR., 2006, p. 30).

Para o que nos interessa comentar, basta tentarmos explicar que, se no campo teórico esses processos estão "aparentemente separados", na prática, esses três níveis

\footnotetext{
${ }^{4}$ Esse ensaio foi escrito e publicado pela primeira vez nas abas do livro O banquete, de Mário de Andrade. Prefácio de Jorge Coli e Luiz Carlos da Silva Dantas. São Paulo: Duas Cidades, 1989 (cf. Sobre os textos. In: MELLO E SOUZA, 2005, p. 181).

${ }^{5}$ Bento Prado Jr. toma como referência "A pintura, textos essenciais, Vol. 8, Descrição e Interpretação. Direção geral de Jacqueline Lichenstein. Apresentação de Jean-François Grouiler. São Paulo: Ed. 34, 2005”, cf. nota de rodapé 47, do próprio autor, em “Entre Narciso e o colecionador ou o ponto cedo do criador", 2006, p. 30.
} 
se interrelacionam desde o início da interpretação de uma obra de arte, assim como suas respectivas instâncias estão dentro de cada nível interrelacionadas. Nas palavras de Panofsky (2007, p. 64): “Assim sendo, no trabalho real, os métodos de abordagem que aqui aparecem como três operações de pesquisas irrelacionadas entre si, fundem-se num mesmo processo orgânico e indivisível".

Ora, tanto a interpretação proposta por Mello e Souza, em Sobre O banquete, quanto em Variações sobre Michelangelo Antonioni, sugerem relativamente essa abordagem esquemática relacional. Em ambos os ensaios vemos a divisão ternária bem marcada intensivamente por Mello e Souza, ou seja, a ensaísta aponta a leitura de um nível primário, ou mais superficial, como o da "Crônica" ou o "da obtenção da naturalidade", respectivamente, até a uma camada significativamente mais profunda, o da "Estética" na obra de Mário, ou o da "profanação da mulher", no filme de Antonioni.

Contudo, não podemos esquecer o problema da circularidade da interpretação neste "esquema relacional", a retroação de um nível e suas instâncias sobre o nível seguinte $^{6}$, que Panofsky, segundo Prado Jr., tenta solucionar seguindo Ernst Cassirer. Em Gilda de Mello e Souza, diz nosso comentador, é "reconhecida a circularidade da interpretação" (PRADO JR., 2006, p. 35). E, assim como Panofsky, ela também à sua maneira se interessa pelos "códigos", pelos "sinais e significações": as inversões ou as substituições de sentido de um mesmo objeto, por exemplo, como vemos em vários ensaios de A idéia e o figurado.

Para Prado Jr., entretanto, o trabalho iconológico de Mello e Souza difere, no espírito, do trabalho de Panofsky. A respeito dos dois críticos, escreve Prado Jr. (2006, p. 32): "Numa palavra, tanto num caso como no outro temos obras primas de iconologia. Mas uma iconologia praticada segundo espíritos diferentes". E talvez seja esse o fato que atesta a relativização do método de interpretação do crítico de arte alemão pela ensaísta brasileira.

Tentando sintetizar algumas ideias de Prado Jr., teríamos, do lado do alemão, a valorização da epistemologia, pois há uma aproximação das interpretações das obras de arte de Panofsky aos "métodos das hard sciences" (PRADO JR., 2006, p. 33) tradicionais, como, por exemplo, a epistemologia de Cassirer; ao passo que, do lado da brasileira, a reflexão estética "volta-se para o futuro", aproximando "a tarefa cognitiva mais da própria arte do que da ciência" (PRADO JR., 2006, p. 34). No limite, por um lado, vemos um espírito crítico mais científico, voltado para os centros das discussões avançadas e, por outro, um espírito crítico mais artístico, localizado nas "bordas" daquelas discussões, mais próximo das "feiras artesanais".

Na expressão de Prado Jr. (2006, p. 34): "Situada na periferia do capitalismo, não poderia ser outro o itinerário de Gilda, nossa mestra de Estética". Os ensaios de Mello e Souza caminham justamente neste campo periférico, em ruas marginais pouco consideradas, bastante artesanais, uma vez que não são trajetos especializados, calculados, consagrados pela Ciência, enaltecidos pelo conhecimento, pela Razão etc..

O seu espírito crítico talvez seja mais remanescente, por isso, de uma estética à la Jean Maugüé, que, enquanto seu professor, a influenciou "[..] na habilidade de desentranhar a filosofia do acontecimento, do cotidiano, da notícia de jornal", aprendendo, por exemplo, como a própria Mello e Souza declara, a "olhar um quadro" (MELLO E

\footnotetext{
${ }^{6}$ Talvez a leitura na íntegra da passagem de Bento Prado Jr. sobre a constituição da circularidade seja mais esclarecedora que tentarmos resumir essa querela. Diz-nos o comentador: "O leitor há de notar que, em cada nível, a fonte subjetiva da percepção encontra-se situada entre seu objeto e o corretivo que lhe permite modificar o sentido da primeira figura apresentada pelo objeto. Mais do que isso, ao passar do nível um ao nível dois, esse efeito retroativo se repete: o corretivo tipológico não altera apenas o sentido semântico, mas retroage sobre o sentido fenomênico. E, mais ainda, no último nível, o corretivo que passa pela História Geral da[s] Idéias, revelando o sentido documental depois de levar o sujeito à consciência da ligação do comportamento (ou do estilo da existência) a uma Weltanschauung, também retroage sobre os níveis anteriores, fechando uma espécie de círculo ao dar a última e complexa forma ao raso sentido fenomênico de que partimos (ou de que parte sempre a percepção espontânea)." (PRADO JR., 2006, pp. 30-1, itálicos do autor)
} 
SOUZA, 2009b, p. 12). Ou, mais próxima ainda, de uma estética vanguardista como a de seu professor Roger Bastide (de quem foi assistente assumindo a Cadeira de Sociologia I, na Universidade de São Paulo), de uma

[...] arte pobre, isto é, uma estética que voltando as costas para os grandes períodos e as grandes manifestações artísticas, fosse desentranhar o fenômeno estético do cotidiano, dos fatos insignificantes e sem foros de grandeza, que compõem, no entanto, o tecido de nossa vida (MELLO E SOUZA, 2009b, p. 41).

Observamos apenas que nessa passagem - última fala de Mello e Souza como professora regular do Departamento de Filosofia da FFLCH-USP em 1972 -, ao analisar o modo criativo de um de seus professores, por ela considerado longe do "prestígio reconhecido da Razão", acabou de algum modo descrevendo, indiretamente, o seu próprio "fazer estético", com seu modo sutil de costurar as palavras e de compor a vida.

\section{Considerações finais}

Por meio das leituras estrutural e genealógica e com o apoio dos comentários de Otília Arantes e Bento Prado Jr., nossa intenção foi mostrar que, em $A$ idéia e o figurado, Gilda de Mello e Souza pousa seu olhar no fim do século XIX e ao longo de quase todo o século XX, com uma voz atual, revigorando o cenário da crítica brasileira sobre a arte.

Entretanto, um estudo mais aprofundado relacionando o exercício crítico de Mello e Souza em referida obra com seus demais trabalhos publicados - desde a tese O espirito das roupas: a moda no século XIX (1985), escrito em 1950, até a obra póstuma A palavra afiada (2014), organizada por Walnice Nogueira Galvão -, em aliança com a tardia e crescente fortuna crítica disponível, em especial o livro Gilda, a paixão pela forma (2007), talvez nos permita circunscrever melhor o seu modo de pensar estético e, consequentemente, apontar os limites desta nossa incipiente discussão.

Isto não nos impede de arriscar dizer, por enquanto, a partir do que foi desenvolvido anteriormente, que Mello e Souza pode ser considerada a expressão contemporânea de uma crítica de cunho social, cuja atuação interpretativa renova as abordagens indiciária e iconológica, mas que, sobretudo, procura reinventar a realidade, "a paisagem", tal como faz a arte, conforme ela mesma diz a respeito de sua geração, no final do ensaio O mestre de Apipucos e o turista aprendiz:

Mas naquele momento de transição entre o sonho das vanguardas e a chegada vitoriosa dos especialistas, delineavam à nossa frente um recorte novo da realidade. Talvez uma invenção da realidade, como de tempos em tempos a arte efetua, para renovar o sentimento da divindade, do homem ou, mais humildemente, da paisagem (MELLO E SOUZA, 2005, p. 70, grifos da autora).

Quem sabe com o tempo, relendo seus ensaios, desdobrando as dobras de seu pensamento, alinhavando seus percursos reflexivos, assimilando seu espírito crítico imanente e reconhecendo suas contribuições na cena crítica da arte brasileira possamos encontrar, também nós, uma maneira, se não sutil e elegante, ao menos humilde de reinventar pela arte a realidade em que se desponta o Brasil do século XXI, já há muito visionado pela força projetivamente crítica de Gilda de Mello e Souza, crítica, aliás, que resiste ao tempo presente.

Endereço de Correspondência: Carlos Henrique dos Santos Fernandes. Universidade Federal de São Carlos - UFSCar, Rodovia Washington Luís, Km 235, s/n, Jardim Guanabara, CEP13565-905, São Carlos, SP, Brasil. E-mail: krlos_mus@hotmail.com 


\section{Bibliografia}

ARANTES, O. B. F. Entrevista com Otília Beatriz Fiori Arantes. In: Rapsódias, n² 2, 2002, pp. 221-264. Disponível em: http:/ / revistas.usp.br/rapsodia/article/view/106413/105051. Acessado em 22/09/2015.

. Notas sobre o método de Gilda de Mello e Souza. In: Revista do Instituto de Estudos Brasileiros. São Paulo: n43, setembro de 2006, pp. 37-49. Disponível em: http: / / www.revistas.usp.br / $\mathrm{rieb/article/view/34542/37280.} \mathrm{Acessado} \mathrm{em} \mathrm{11/10/2015.}$

DELEUZE, G. Proust e os signos. Rio de Janeiro, Forense Universitária, 2006.

PANOFSKY, E. 1. Iconografia e iconologia: uma introdução ao estudo da arte da renascença. In: Significado nas artes visuais. São Paulo, Perspectiva, 2007, pp. 47-87.

PRADO JR., B. Gilda de Mello e Souza. In: Discurso, nº 26, pp. 15-17. Disponível em: http:/ / filosofia. fflch.usp.br/publicacoes/discursoD26. Acessado em 22/09/2015.

. Narciso e o colecionador ou o ponto cego da criação. In: Revista do Instituto de Estudos Brasileiros. São Paulo, n43, setembro de 2006, pp. 09-36. Disponível em: http: / / www.revistas.usp.br /

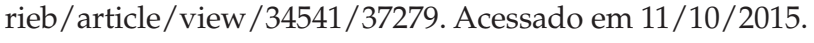

RIBEIRO, R. J. Apresentação. In: Discurso, nº 26, 1996, pp. 09-13. Disponível em: http:/ /filosofia.fflch. usp.br/publicacoes/discursoD26.

MELLO E SOUZA, G. R. A idéia e o figurado. $1^{a}$ ed. São Paulo, Duas Cidades; Ed. 34, 2005. (Coleção Espírito Crítico)

. A Estética rica e a Estética pobre dos professores franceses. In: Exercícios de leitura. 2a ed., São Paulo, Duas Cidades; Ed. 34, 2009b, pp. 09-41. (Coleção Espírito Crítico) . Paulo Emílio: a crítica como perícia. In: Exercícios de leitura. $2^{\mathrm{a}}$ ed. São Paulo, Duas Cidades; Ed. 34, 2009a, pp. 259-270. (Coleção Espírito Crítico)

. O tupi e o alaúde: uma interpretação de Macunaíma. $2^{\text {a }}$ ed., São Paulo, Duas Cidades; Ed. 34, 2003. (Coleção Espírito Crítico)

MELLO E SOUZA, G. R.; MELLO E SOUZA, A. C. A lembrança que guardo de Mário. In: Revista do Instituto de Estudos Brasileiros, $n^{\circ} 36,1994$, pp. 09-25. Disponível em: http:/ /www.ieb.usp.br/ publicacoes/doc/rieb36_1349118927.pdf . Acessado em 1/12/2015. 